\title{
Efficacy and Safety of Percutaneous Transhepatic Cholangioscopy with the Spyglass DS Direct Visualization System in Patients with Surgically Altered Anatomy: A Pilot Study
}

\author{
Hyung Ku Chon ${ }^{1,2}$, Keum Ha Choi ${ }^{3}$, Sang Hyun $\mathrm{Seo}^{4}$, and Tae Hyeon $\mathrm{Kim}^{1,2}$ \\ ${ }^{1}$ Division of Biliopancreas, Department of Internal Medicine, ${ }^{2}$ Institute of Wonkwang Medical Science, Departments of ${ }^{3}$ Pathology and \\ ${ }^{4}$ Radiology, Wonkwang University Hospital, Wonkwang University College of Medicine, Iksan, Korea
}

See editorial on page 1.

\section{Article Info}

Received January 22, 2021

Revised February 25, 2021

Accepted March 11, 2021

Published online June 25, 2021

\section{Corresponding Author}

Tae Hyeon Kim

ORCID https://orcid.org/0000-0002-9723-2136

E-mail kth@wku.ac.kr
Background/Aims: Percutaneous transhepatic cholangioscopy (PTCS) is used for the diagnosis and treatment of biliary diseases in patients with failed endoscopic retrograde cholangiopancreatography, particularly those with surgically altered anatomy. However, few studies are available on the clinical use of Spyglass DS direct visualization system (SpyDS)-assisted PTCS. This study aimed to assess the efficacy and safety of SpyDS-assisted PTCS in patients with surgically altered anatomy, particularly those with a Roux-en-Y reconstruction.

Methods: Thirteen patients (six women, median age 71.4 years [range, 53 to 83 years]) with surgically altered anatomy (four Roux-en-Y choledochojejunostomies, seven Roux-en-Y hepaticojejunostomies, and two Roux-en-Y esophagojejunostomies) who underwent SpyDS-assisted PTCS between January 2019 and August 2020 were included and the data was acquired by retrospectively reviewing electronic medical record.

Results: A total of 19 SpyDS-assisted PTCS procedures were performed in the 13 patients: eight had bile-duct stones, and five had biliary strictures. All SpyDS-assisted PTCS procedures were successfully performed. The total procedure time was $42.42 \pm 18.0$ minutes (mean \pm standard deviation). Bile duct clearance was achieved in all bile duct stone cases after a median of 2 (range, 1 to 3 ) procedures. In the five biliary stricture cases, the results of SpyBite forceps-guided targeted biopsy were consistent with adenocarcinoma (100\% accuracy). The median hospitalization duration was 20 days (range, 14 to 30 days). No procedure-related morbidity or mortality occurred.

Conclusions: SpyDS-assisted PTCS may be a safe, feasible, and effective procedure for the diagnosis and treatment of biliary diseases in patients with surgically altered anatomy, particularly in those with the Roux-en-Y reconstruction requiring a percutaneous approach. However, our findings need to be validated in further studies. (Gut Liver 2022;16:111-117)

Key Words: Endoscopic retrograde cholangiopancreatography; Spyglass; Roux-en-Y anastomosis

\section{INTRODUCTION}

Endoscopic retrograde cholangiopancreatography (ERCP) is the gold standard for the diagnosis and treatment of biliary diseases. However, ERCP failure occurs in approximately $5 \%$ to $20 \%$ of the patients, even in referral centers. ${ }^{1}$ Surgically altered anatomy, particularly long limbs, as in Roux-en-Y reconstruction, may be related to ERCP failure and present a considerable technical chal- lenge. ${ }^{2,3}$ If a conventional endoscopic approach using a duodenoscope, a cap-fitted forward-viewing gastroscope, or baby colonoscope fails, device-assisted enteroscopy (DAE)or endoscopic ultrasound (EUS)-guided intervention may be considered as a secondary modality. ${ }^{4,5}$ These procedures require additional dedicated devices and should be performed by experts. The complication rate of the procedure has been reported to reach $20 \%$ and the steep learning curve associated with the procedure may be problematic. ${ }^{6-8}$ 
Percutaneous transhepatic biliary drainage (PTBD) is an established technique that may be indicated in cases of previously failed ERCP, particularly in those involving a surgically altered anatomy. ${ }^{9,10}$ However, the specimen adequacy and diagnostic sensitivity of tissue obtained through PTBD may be unsatisfactory, and bile duct stone clearance with PTBD alone can be difficult. In such cases, percutaneous transhepatic cholangioscopy (PTCS) may be a suitable option because it allows performing target biopsy and stone fragmentation with laser lithotripsy or electrohydraulic lithotripsy (EHL) under direct visualization. ${ }^{11}$ Before performing a PTCS, fistula dilation to 16-18 $\mathrm{F}$ is required because the external diameter of a percutaneous cholangioscope is 4.1 to $4.9 \mathrm{~mm} .{ }^{12}$ However, with the introduction of the Spyglass DS direct visualization system (SpyDS), which has an outer diameter of $10.5 \mathrm{~F}$, cutaneous biliary fistula dilation of up to only $12 \mathrm{~F}$ has been possible for PTCS. ${ }^{13}$ Compared to the classical approach, this novel technique using SpyDS can reduce the pain associated with tract dilation for bile duct access and can shorten the length of hospital stay. Limited data are available on the outcomes of SpyDS-assisted PTCS for biliary stricture management and bile duct stone removal in patients with surgically altered anatomy. Therefore, this study aimed to evaluate the efficacy and safety of SpyDS-assisted PTCS in patients with a prior Roux-en-Y reconstruction.

\section{MATERIALS AND METHODS}

\section{Patients}

A total of 76 consecutive patients with surgically altered anatomy who were treated for biliary diseases, including biliary stricture or bile duct stones, between January 2019 and August 2020 at Wonkwang University Hospital, were retrospectively reviewed. Of them, 63 patients were excluded for the following reasons: subtotal gastrectomy with
Billroth II anastomosis $(\mathrm{n}=40)$, subtotal gastrectomy with Billroth I anastomosis $(\mathrm{n}=11)$, DAE $(\mathrm{n}=6)$, conventional PTCS ( $\mathrm{n}=2)$, death due to disease progression after PTBD $(\mathrm{n}=2)$, EUS-guided intervention $(\mathrm{n}=1)$, and balloon dilation through PTBD ( $\mathrm{n}=1$ ) (Fig. 1). We evaluated the remaining 13 patients with a prior Roux-en-Y reconstruction who underwent PTCS with SpyDS. The patients' electronic medical records were reviewed for demographic and clinical details, adverse events, findings, procedure reports, and clinical courses. This study was approved by the Institutional Review Board of Wonkwang University Hospital (IRB number: WKUH-2020-11-011) and conducted in accordance with the Declaration of Helsinki. Written informed consent to undergo the procedure was obtained from all patients.

\section{Procedures}

Stepwise percutaneous tract dilation with two sessions was performed by a skilled interventional radiologist (S.H.S.). PTBD was performed under fluoroscopic guidance, with an 8-F catheter inserted into the left intrahepatic duct and/or right intrahepatic bile duct, according to a planned anatomical approach to the stricture or bileduct stones based on radiologic imaging. The percutaneous tract was dilated at least 3 days later by exchanging the 8-F catheter for a $12-\mathrm{F}$ catheter. For sinus tract maturation, PTCS with SpyDS (Boston Scientific, Natick, MA, USA) was performed by two experienced endoscopists (T.H.K. and H.K.C.) at least 9 days after the initial PTBD. A guidewire was inserted into the small bowel lumen through the bilioenteric anastomosis using a PTBD catheter, which was removed thereafter. The SpyDS scope was advanced into the bile duct beside the guidewire. In cases of bile duct stones, predilation of the bilioenteric anastomosis site was performed using an 8-mm balloon (Hurricane RX; Boston Scientific). The stones were fragmented using EHL (EHLProbe; Walz Elektronik, Rohrdorf, Germany) under direct visualization, and were removed by pushing with the tip of

Acute cholangitis with surgically altered anatomy $(n=76)$

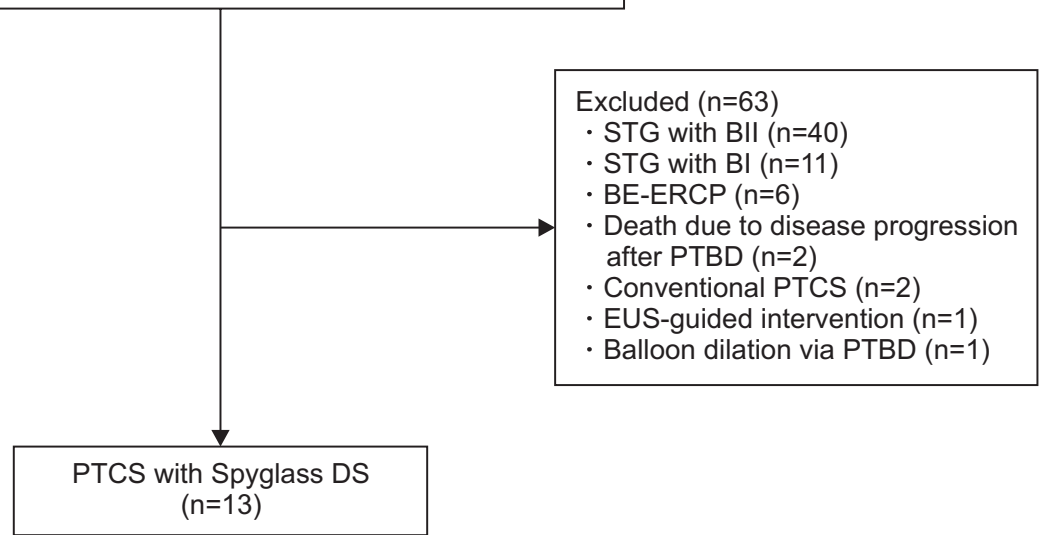

Fig. 1. Flowchart of patient enrollment. STG, subtotal gastrectomy; BI, Billroth I, BII, Billroth II; BE-ERCP, balloon enteroscopy-assisted endoscopic retrograde cholangiopancreatography; PTBD, percutaneous transhepatic biliary drainage; PTCS, percutaneous transhepatic cholangioscopy; EUS, endoscopic ultrasound. 

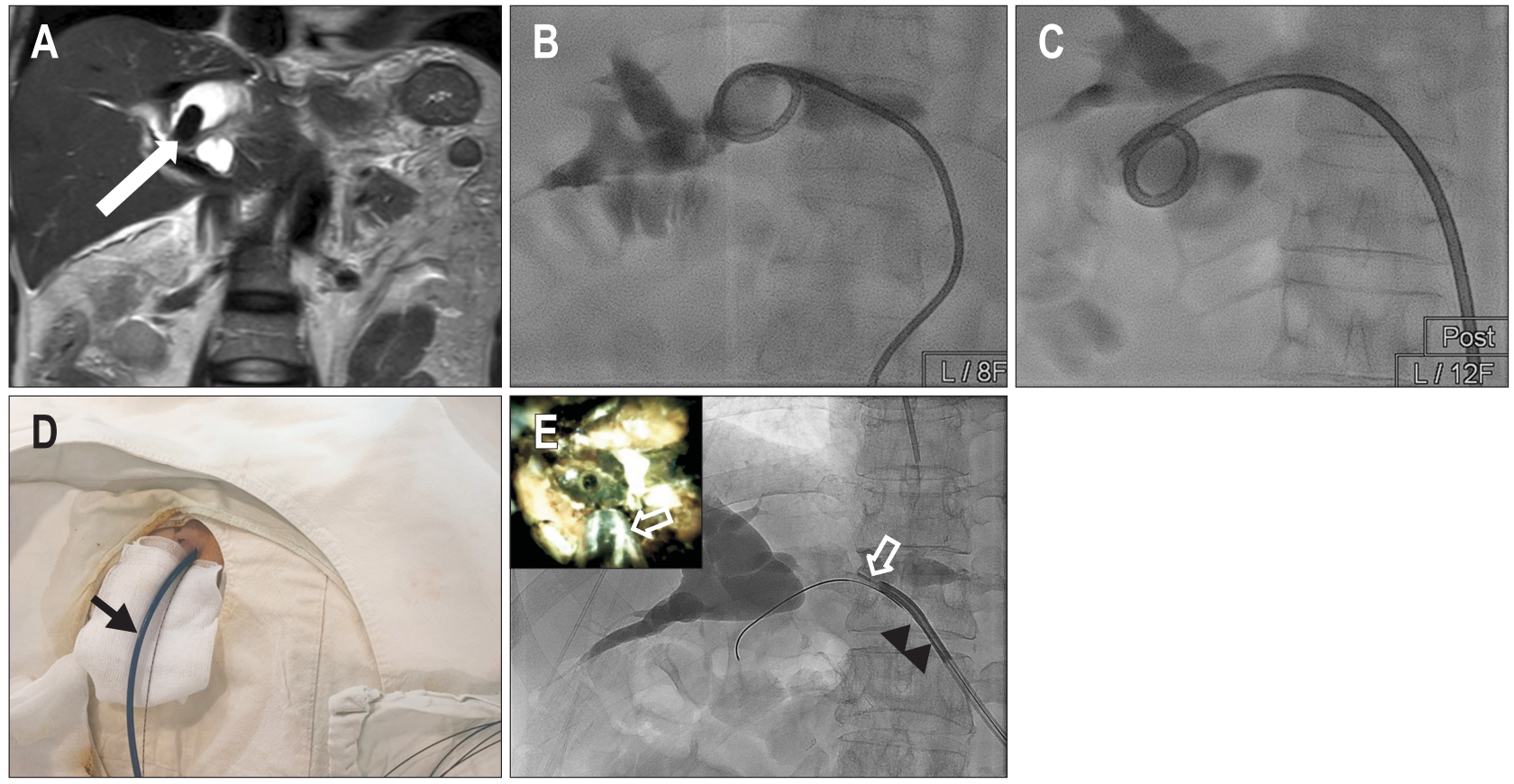

Fig. 2. Spyglass DS direct visualization system (SpyDS)-assisted percutaneous transhepatic cholangioscopy (PTCS) using electrohydraulic lithotripsy (EHL) for intrahepatic bile duct stone removal. (A) Magnetic resonance imaging showed an approximately $2.1 \mathrm{~cm}$ stone (white arrow) in the left intrahepatic bile duct. (B) Initial percutaneous transhepatic biliary drainage with an 8-F catheter was performed. (C) Cutaneobiliary fistula dilation up to $12 \mathrm{~F}$ was performed at least 3 days later. (D) After cutaneous fistula tract maturation, the SpyDS scope (black arrow) was inserted into the left intrahepatic bile duct beside the guidewire. (E) PTCS with SpyDS (black arrowheads)-guided stone fragmentation using EHL (white open arrows) was performed.
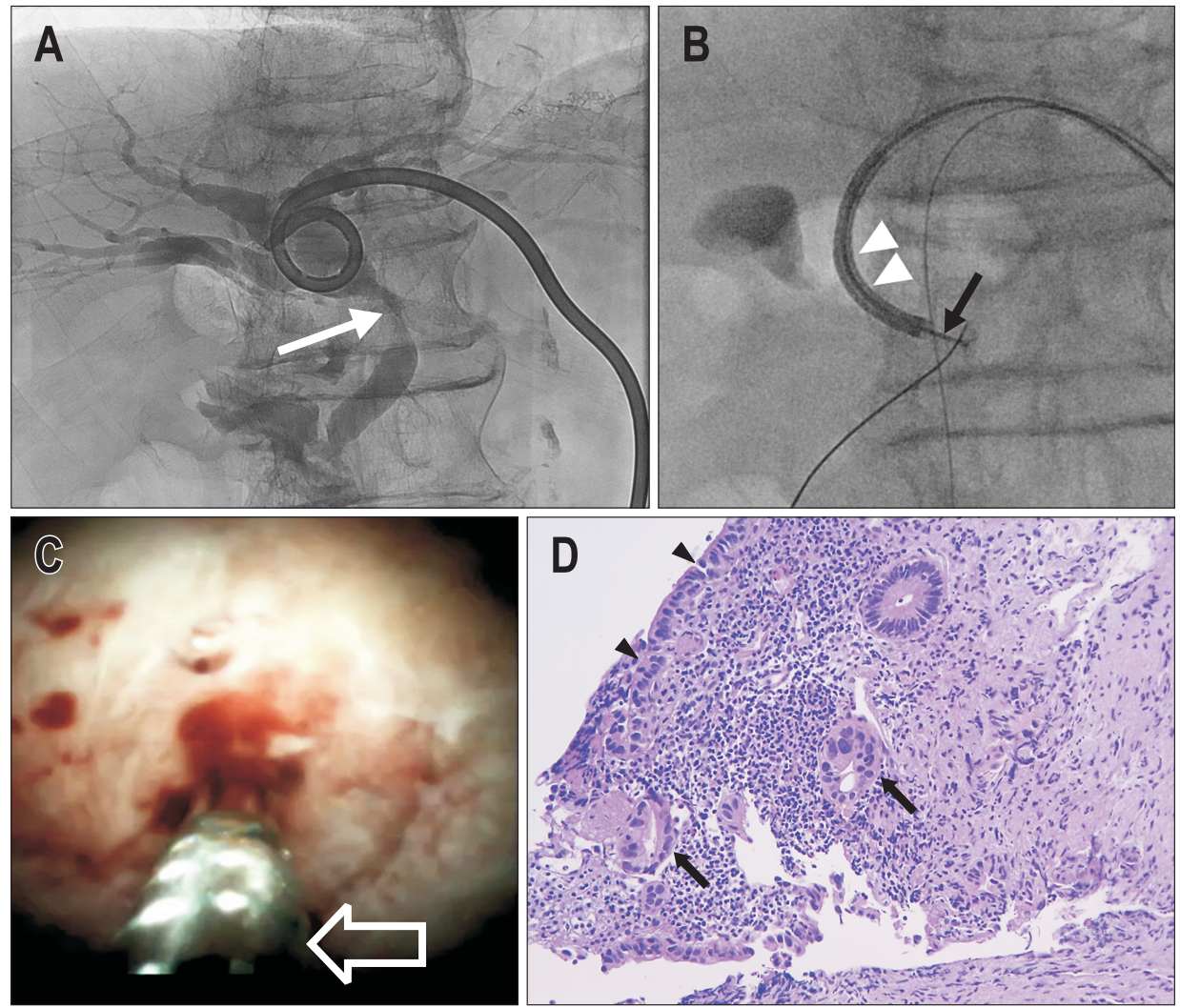

Fig. 3. Spyglass DS direct visualization system (SpyDS)-assisted percutaneous transhepatic cholangioscopy (PTCS) using SpyBite forceps for a biliary stricture. (A) Percutaneous transhepatic cholangiography showed dilatation of the intrahepatic bile duct, with stenosis (white arrow) at the upper third of the common bile duct. (B) SpyDS (white arrowheads)assisted PTCS using SpyBite forceps (black arrow) was performed to evaluate the biliary stricture. (C) Cholangioscopy showed a circumferential mass with tumor vessels at the biliary stricture site, and tissue specimens were obtained using SpyBite forceps (open white arrow). (D) Pathologic examination revealed atypical glands (black arrows) with dysplastic surface epithelium (black arrowheads), compatible with adenocarcinoma $(H \& E, \times 200)$. 


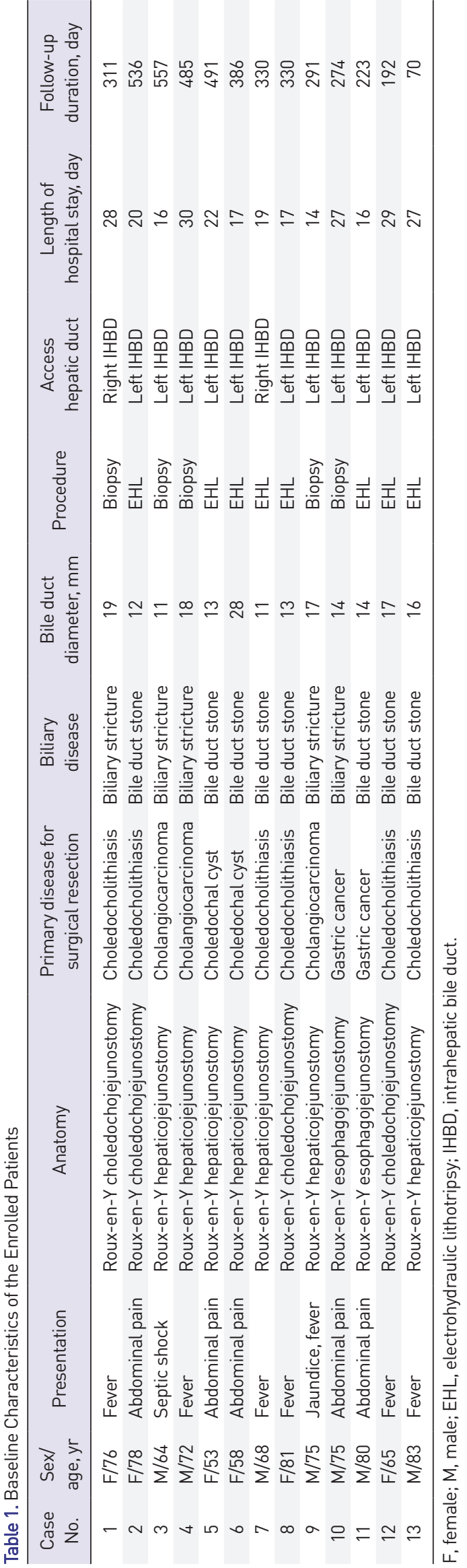

the SpyDS scope, washing with normal saline, or pushing the balloon catheter into the small intestine (Fig. 2). If duct clearance was confirmed by repeating the procedure under direct visualization and cholangiography, the 8-F catheter was inserted and removed 1 to 2 days later based on the follow-up cholangiography. In biliary stricture cases, visual assessment under direct cholangioscopy was performed, and target tissue biopsy using SpyBite forceps (Boston Scientific) was performed in lesions with suspicious malignant features, such as neovascularization or mass formation (Fig. 3). At the end of the procedure, the PTBD catheter was reinserted to drain the biliary tract. An experienced pathologist (K.H.C.) evaluated all specimens. During the procedure, sterile normal saline was continuously applied through an irrigation channel for proper visualization and to avoid cholangiovenous reflux.

\section{Definitions}

The PTCS with SpyDS was considered successful if the SpyDS scope was adequately advanced into the bile duct for proper intervention. Procedure time was recorded from the insertion of the SpyDS scope into the cutaneobiliary fistula to the re-insertion of the PTBD catheter. Duct clearance was considered successful when cholangiography and direct cholangioscopy revealed a clear duct. Procedurerelated adverse events were investigated by reviewing the medical records, laboratory results, and images, including cholangiography, follow-up computed tomography scans, or magnetic resonance images, after the procedure.

\section{RESULTS}

The baseline characteristics and clinical data of the patients included in this study are shown in Table 1 and Supplementary Table 1. A total of 19 PTCS procedures using SpyDS were performed in the 13 patients (six women, median age 71.4 years [range, 53 to 83 years]), eight of whom had bile duct stones and five had a biliary stricture. All SpyDS-assisted PTCS procedures were successfully performed, and no procedure-related morbidity or mortality was observed. For the 19 procedures in the current study, the total procedure time was $42.42 \pm 18.0$ minutes (mean \pm standard deviation). The median length of hospitalization and the median follow-up period were 20 days (range, 17 to 30 days) and 330 days (range, 70 to 536 days), respectively.

Successful bile duct stone removal was achieved in all cases after PTCS with SpyDS (8/8). The median maximum bile duct stone size and the median number of stones were $15.5 \mathrm{~mm}$ (range, 13 to $37 \mathrm{~mm}$ ) and 5 (range, 1 to 8 ), respec- 
tively. The median total number of sessions until complete stone clearance was 2 (range, 1 to 3), and EHL was used for stone fragmentation in all cases of bile duct stones (Table 2). No recurrence was observed during the follow-up.

SpyBite forceps-guided target biopsies were successful in all five cases of biliary stricture. Papillary/circumferential masses and irregular surfaces with neovascularization, suggestive of malignancy, were observed under direct cholangioscopy in all cases. The specimens obtained using SpyBite forceps were found to be adequate for pathologic evaluation and were consistent with adenocarcinoma. The final diagnoses were as follows: recurrent cholangiocarcinoma $(n=3)$ and cholangiocarcinoma $(n=2)$. Of the three patients with recurrent cholangiocarcinoma, one patient underwent surgical resection and two patients received chemotherapy with placement of a biliary metal stent. Of the two patients diagnosed with cholangiocarcinoma, one patient died of pneumonia, disseminated intravascular coagulation, and acute kidney injury 311 days later, and the other patient underwent intraductal radiofrequency ablation with placement of a metal stent through PTBD (Table 3).

\section{DISCUSSION}

In an era of advanced endoscopic procedures, including ERCP, EUS, and DAE, the need for PTCS, which can directly visualize the bile duct, has been reduced. However, in some cases in which the endoscopic approach is technically difficult, such as in patients with a Roux-en-Y reconstruction, PTCS can be a valuable procedure. ${ }^{14}$ However, few studies on PTCS performed with SpyDS have been

Table 2. Clinical Outcomes of the Enrolled Patients with Bile Duct Stones

\begin{tabular}{|c|c|c|c|c|c|c|c|c|c|}
\hline $\begin{array}{l}\text { Case } \\
\text { No. }\end{array}$ & $\begin{array}{l}\text { Sex/ } \\
\text { age, yr }\end{array}$ & $\begin{array}{l}\text { Technical } \\
\text { success }\end{array}$ & $\begin{array}{l}\text { Total number of session until } \\
\text { complete stone removal }\end{array}$ & $\begin{array}{l}\text { Removal } \\
\text { method }\end{array}$ & $\begin{array}{c}\text { Maximum bile } \\
\text { duct stone size, } \mathrm{mm}\end{array}$ & $\begin{array}{l}\text { No. of } \\
\text { stones }\end{array}$ & $\begin{array}{c}\text { Duct } \\
\text { clearance }\end{array}$ & $\begin{array}{l}\text { Procedure } \\
\text { time, min }\end{array}$ & $\begin{array}{c}\text { Adverse } \\
\text { events }\end{array}$ \\
\hline 2 & $\mathrm{~F} / 78$ & Yes & 1 & $\mathrm{EHL}$ & 21 & 4 & Yes & 52 & No \\
\hline 5 & $F / 53$ & Yes & 2 & EHL & 16 & 8 & Yes & $\begin{array}{l}\text { First: } 52 \\
\text { Second: } 51\end{array}$ & No \\
\hline 6 & $F / 58$ & Yes & 2 & $\mathrm{EHL}$ & 21 & 1 & Yes & $\begin{array}{l}\text { First: } 31 \\
\text { Second: } 18\end{array}$ & No \\
\hline 7 & $M / 68$ & Yes & 2 & $\mathrm{EHL}$ & 13 & 6 & Yes & $\begin{array}{l}\text { First: } 71 \\
\text { Second: } 80\end{array}$ & No \\
\hline 8 & $F / 81$ & Yes & 1 & $\mathrm{EHL}$ & 13 & 5 & Yes & 42 & No \\
\hline 11 & $M / 80$ & Yes & 2 & $\mathrm{EHL}$ & 15 & 6 & Yes & $\begin{array}{l}\text { First: } 41 \\
\text { Second: } 21\end{array}$ & No \\
\hline 12 & $F / 65$ & Yes & 3 & $\mathrm{EHL}$ & 37 & 3 & Yes & $\begin{array}{l}\text { First: } 52 \\
\text { Second: } 59 \\
\text { Third: } 43\end{array}$ & No \\
\hline 13 & $M / 83$ & Yes & 1 & EHL & 15 & 5 & Yes & 63 & No \\
\hline
\end{tabular}

F, female; M, male; EHL, electrohydraulic lithotripsy.

Table 3. Clinical Outcomes of the Enrolled Patients with Indeterminate Stricture

\begin{tabular}{|c|c|c|c|c|c|c|c|c|c|}
\hline $\begin{array}{l}\text { Case } \\
\text { No. }\end{array}$ & $\begin{array}{l}\text { Sex/ } \\
\text { age, yr }\end{array}$ & $\begin{array}{l}\text { Total No. of } \\
\text { sessions }\end{array}$ & $\begin{array}{l}\text { Technical } \\
\text { success }\end{array}$ & $\begin{array}{l}\text { Procedure } \\
\text { time (min) }\end{array}$ & Findings of SpyDS & $\begin{array}{l}\text { Adverse } \\
\text { events }\end{array}$ & Histopathology & $\begin{array}{c}\text { Final } \\
\text { diagnosis }\end{array}$ & $\begin{array}{l}\text { Treatment/ } \\
\text { follow-up }\end{array}$ \\
\hline 1 & $F / 76$ & 1 & Yes & 25 & $\begin{array}{l}\text { Papillary mass with } \\
\text { tortuous vessels }\end{array}$ & No & Adenocarcinoma & $\mathrm{CC}$ & Death* \\
\hline 3 & $M / 64$ & 1 & Yes & 27 & $\begin{array}{l}\text { Irregular surface and } \\
\text { circumferential mass } \\
\text { with tumor vessel }\end{array}$ & No & Adenocarcinoma & Recurred CC & $\begin{array}{l}\text { Chemotherapy } \\
\text { with metal } \\
\text { stenting }\end{array}$ \\
\hline 4 & $\mathrm{M} / 72$ & 1 & Yes & 31 & $\begin{array}{l}\text { Circumferential mass } \\
\text { with tumor vessel and } \\
\text { easy oozing }\end{array}$ & No & Adenocarcinoma & Recurred CC & Surgery \\
\hline 9 & $M / 75$ & 1 & Yes & 23 & $\begin{array}{l}\text { Papillary mass with } \\
\text { tortuous vessels }\end{array}$ & No & Adenocarcinoma & Recurred CC & $\begin{array}{l}\text { Chemotherapy } \\
\text { with metal } \\
\text { stenting }\end{array}$ \\
\hline 10 & $M / 75$ & 1 & Yes & 24 & $\begin{array}{l}\text { Circumferential mass } \\
\text { with tumor vessel }\end{array}$ & No & Adenocarcinoma & $\mathrm{CC}$ & $\begin{array}{l}\text { Intraductal RFA } \\
\text { with metal } \\
\text { stenting }\end{array}$ \\
\hline
\end{tabular}

SpyDS, Spyglass DS direct visualization system; F, female; M, male; CC, cholangiocarcinoma; RFA, radiofrequency ablation.

*The patient died 311 days after the procedure from pneumonia, disseminated intravascular coagulation, and acute kidney injury. 
conducted to date.

SpyDS-assisted PTCS offers several advantages over the traditional PTCS as follows: (1) it can be performed with a 12-F cutaneobiliary fistula, which requires less time and causes less pain; (2) a four-way deflected steering allows for maneuverability of the scope; (3) it has a low risk of devicetransmitted infection owing to its sterile packaging; and (4) a dedicated irrigation channel maintains clear visualization of the bile duct. Furthermore, the newly developed SpyDS technology offers improved imaging quality with a wider field of view and more easily passed accessory instruments than the first-generation Spyglass system. ${ }^{15}$

Our study demonstrated the safety, feasibility, and diagnostic and therapeutic success of SpyDS-assisted PTCS in patients with a prior Roux-en-Y reconstruction. The technical success rate was 100\% (13/13). SpyDS-assisted PTCS with EHL for bile duct stone removal achieved complete duct clearance in all cases (9/9). Additionally, in patients with a biliary stricture, the diagnostic accuracy of both optical target biopsy using SpyBite forceps and visual assessment with SpyDS was 100\%. Du et al. ${ }^{16}$ reported their experience with PTCS using SpyDS for the evaluation of biliary strictures in four patients with failed conventional ERCP (one with biliary cannulation failure, three with altered biliary-intestinal anatomy). Although the authors showed the feasibility, safety, and high accuracy of the procedure, their results were limited because of the lack of follow-up of outcomes and the noninclusion of cases with bile duct stones which were present in our study. Tripathi et $a l^{17}$ reported that procedures involving five patients with Roux-en-Y reconstruction managed with SpyDS-guided PTCS were technically successful and did not result in any adverse events. The authors suggested that SpyDS-guided PTCS may be considered for various diagnostic and therapeutic indications, including biliary stricture management, biliary tract biopsy, bile duct stone removal, and undiagnosed biliary stasis evaluation, particularly in patients with a surgically altered anatomy. As more patients were included in our study than in the study by Tripathi et al., ${ }^{17}$ our study provides more preliminary evidence on the safety and effectiveness of PTCS using SpyDS in patients with a prior Roux-en-Y reconstruction. However, complete stone removal with PTCS would be difficult in cases of bile duct stones along multiple intrahepatic bile ducts; thus, proper selection of patients is crucial for procedural success. In the present study, as the bile duct stones were within a single intrahepatic duct or in the common bile duct in all cases, the procedure could be successfully performed.

The overall adverse event and mortality rates related to PTCS using a conventional cholangioscope have been reported to be $6 \%$ to $17 \%$ and $0 \%$ to $0.6 \%$, respectively. ${ }^{14,18,19}$
However, in our study, no procedural adverse events occurred. Most of the adverse events reported in patients undergoing PTCS occurred during the preparatory stages, including initial PTBD insertion and tract dilation. In the current study, initial bile duct puncture and catheter insertion for PTBD were technically convenient because the median bile duct diameter was $14 \mathrm{~mm}$ (range, 11 to $28 \mathrm{~mm}$ ). Complications related to tract dilation could be eliminated because tract dilation only up to $12 \mathrm{~F}$ was required. We considered that the lack of adverse events could be explained by performing PTCS with SpyDS after improving cholangitis through sufficient antibiotic treatment with maintenance of the PTBD catheter and implementation of continuous irrigation with sterile normal saline during SpyDS-assisted PTCS.

PTCS procedures require a shorter distance to access the bile duct than the endoscopic approach. However, the relatively long length of the SpyDS scope (because the SpyDS was originally designed to be inserted into an accessory channel in a duodenoscope for a peroral approach) may be troublesome. The development of a shorter SpyDS scope for PTCS could make the procedure more convenient. Furthermore, compared to the conventional PTCS, SpyDSassisted PTCS has several drawbacks as follows: (1) lower image quality, (2) lack of image-enhanced function, and (3) limited dedicated accessories owing to a relatively smaller accessory channel. The clinical impact of SpyDS on biliary diseases can progress if these shortcomings are improved.

The current study had several limitations. First, it was a retrospective, small-scale, single-center pilot investigation. Second, as a single-arm study, no comparison was made with other methods, including conventional PTCS, EUSguided intervention, or DAE, with respect to procedural pain or length of hospitalization. Third, our results were limited by the lack of evaluation of long-term outcomes. Fourth, no analysis on cost-effectiveness was performed. However, because the reimbursement of SpyDS varies across different countries, it is difficult to analyze costs in a generalized manner. Despite these limitations, our results are expected to play an important role in future research.

In conclusion, SpyDS-assisted PTCS may be a safe, feasible, and effective diagnostic and therapeutic intervention for biliary diseases in patients with a surgically altered anatomy, especially in those who had undergone a Rouxen-Y reconstruction and require a percutaneous approach. However, our findings need to be validated by further studies.

\section{CONFLICTS OF INTEREST}

No potential conflict of interest relevant to this article 
was reported.

\section{ACKNOWLEDGEMENTS}

This study was supported by Wonkwang University 2021. The author thanks Eun Ha Lee, So Hyung Park, Sung Ju Kim, and In Hee So of the Wonkwang University Hospital for assistance with the procedures. In addition, the author is grateful for the dedication of Hee Heun Kim and Ju Hee Ahn of the Wonkwang University Hospital as physician assistants.

\section{AUTHOR CONTRIBUTIONS}

Conceptualization: T.H.K. Data curation: H.K.C., K.H.C., S.H.S. Formal analysis: H.K.C. Funding acquisition: H.K.C. Methodology: H.K.C. Project administration: T.H.K. Visualization: H.K.C., K.H.C. Writing - original draft: H.K.C., K.H.C. Writing - review \& editing: T.H.K., S.H.S. Approval of final manuscript: all authors.

\section{ORCID}

Hyung Ku Chon https://orcid.org/0000-0002-6068-3849 Keum Ha Choi https://orcid.org/0000-0001-8617-4869 Sang Hyun Seo https://orcid.org/0000-0003-0708-4051 Tae Hyeon Kim https://orcid.org/0000-0002-9723-2136

\section{SUPPLEMENTARY MATERIALS}

Supplementary materials can be accessed at https://doi. org/10.5009/gnl210028.

\section{REFERENCES}

1. Williams EJ, Taylor S, Fairclough P, et al. Are we meeting the standards set for endoscopy? Results of a large-scale prospective survey of endoscopic retrograde cholangiopancreatograph practice. Gut 2007;56:821-829.

2. Park CH. Experience of endoscopists in endoscopic retrograde cholangiopancreatography in surgically altered anatomy patients. Clin Endosc 2020;53:7-8.

3. Samarasena JB, Nguyen NT, Lee JG. Endoscopic retrograde cholangiopancreatography in patients with roux-en-Y anatomy. J Interv Gastroenterol 2012;2:78-83.

4. Saumoy M, Kahaleh M. Safety and complications of interven- tional endoscopic ultrasound. Clin Endosc 2018;51:235-238.

5. Tsutsumi K, Kato H, Yabe S, et al. A comparative evaluation of treatment methods for bile duct stones after hepaticojejunostomy between percutaneous transhepatic cholangioscopy and peroral, short double-balloon enteroscopy. Therap Adv Gastroenterol 2017;10:54-67.

6. Krutsri C, Kida M, Yamauchi H, Iwai T, Imaizumi H, Koizumi W. Current status of endoscopic retrograde cholangiopancreatography in patients with surgically altered anatomy. World J Gastroenterol 2019;25:3313-3333.

7. Yane K, Katanuma A, Maguchi H, et al. Short-type singleballoon enteroscope-assisted ERCP in postsurgical altered anatomy: potential factors affecting procedural failure. Endoscopy 2017;49:69-74.

8. Shah RM, Tarnasky P, Kedia P. A review of endoscopic ultrasound guided endoscopic retrograde cholangiopancreatography techniques in patients with surgically altered anatomy. Transl Gastroenterol Hepatol 2018;3:90.

9. Schumacher B, Othman T, Jansen M, Preiss C, Neuhaus H. Long-term follow-up of percutaneous transhepatic therapy (PTT) in patients with definite benign anastomotic strictures after hepaticojejunostomy. Endoscopy 2001;33:409-415.

10. Weber A, Gaa J, Rosca B, et al. Complications of percutaneous transhepatic biliary drainage in patients with dilated and nondilated intrahepatic bile ducts. Eur J Radiol 2009;72:412-417.

11. Kim MH, Yasuda K. Percutaneous transhepatic cholangioscopic examination: a necessity for the biliary endoscopist. Gastrointest Endosc 2001;53:695-697.

12. Ross AS, Kozarek RA. Cholangioscopy: where are we now? Curr Opin Gastroenterol 2009;25:245-251.

13. Derdeyn J, Laleman W. Current role of endoscopic cholangioscopy. Curr Opin Gastroenterol 2018;34:301-308.

14. Oh HC. Percutaneous transhepatic cholangioscopy in bilioenteric anastomosis stricture. Clin Endosc 2016;49:530-532.

15. Karagyozov P, Boeva I, Tishkov I. Role of digital single-operator cholangioscopy in the diagnosis and treatment of biliary disorders. World J Gastrointest Endosc 2019;11:31-40.

16. Du L, D'Souza P, Thiesen A, et al. Percutaneous transhepatic cholangioscopy for indeterminate biliary strictures using the SpyGlass system: a case series. Endoscopy 2015;47:1054-1056.

17. Tripathi N, Mardini H, Koirala N, Raissi D, Emhmed Ali SM, Frandah WM. Assessing the utility, findings, and outcomes of percutaneous transhepatic cholangioscopy with Spyglass ${ }^{\mathrm{TM}}$ Direct visualization system: a case series. Transl Gastroenterol Hepatol 2020;5:12.

18. Hwang MH, Tsai CC, Mo LR, et al. Percutaneous choledochoscopic biliary tract stone removal: experience in 645 consecutive patients. Eur J Radiol 1993;17:184-190.

19. Ponchon T, Genin G, Mitchell R, et al. Methods, indications, and results of percutaneous choledochoscopy: a series of 161 procedures. Ann Surg 1996;223:26-36. 